\title{
PERFIL METABÓLICO DE OVELHAS SANTA INÊS EM DIFERENTES FASES DE GESTAÇÃO CRIADAS EM SISTEMA SEMI-INTENSIVO NO ESTADO DO AMAZONAS
}

\author{
Roseane Pinto Martins de Oliveira ${ }^{1}$, Alen Henrique Passos Maduro ${ }^{2}$, Emerson Silva Lima ${ }^{1}$, \\ FRANKLYN FERREIRA DE OLIVEIRA ${ }^{3}$ \\ ${ }^{1}$ Professores Doutores da Universidade Federal do Amazonas, Manaus, AM, Brasil. roseane@ufam.edu.br \\ ${ }^{2}$ Pós-Graduando do Instituto Nacional de Pesquisas da Amazônia, Manaus, AM, Brasil. \\ ${ }^{3}$ Médico Veterinário Autônomo, Manaus, AM, Brasil.
}

O objetivo deste trabalho foi avaliar a condição metabólica nutricional de ovelhas em diferentes fases de gestação. A análise do perfil metabólico foi feita por meio da coleta de sangue, utilizando-se 30 ovelhas distribuídas em três grupos de acordo com a fase de gestação (dias), sendo G1: entre 50 e 60 dias; G2: entre 80 e 90 dias; e G3: entre 130 e 140 dias. As análises dos metabólitos foram realizadas por kits comerciais. As concentrações de proteínas totais, albumina, globulinas e ureia não diferiram entre si, com exceção da ureia que apresentou níveis aumentados. As médias de glicose mantiveram-se abaixo do valor normal mínimo. Para colesterol, as médias foram $89,86 \mathrm{mg} / \mathrm{dL}, 86,01 \mathrm{mg} / \mathrm{dL}$ e $92,23 \mathrm{mg} / \mathrm{dL}$ para o G1, G2 e G3, respectivamente. Os animais do G1 e G2 tiveram médias de triglicerídeos estatisticamente iguais, diferindo dos animais do G3. As médias de $\beta$ hidroxibutirato mantiveram-se dentro da referência. Os níveis de cálcio estiveram abaixo da referência, observando-se o valor mais baixo no $\mathrm{G} 3(8,86 \mathrm{mg} / \mathrm{dL})$. Os níveis de fósforo apresentaram-se diminuídos no G3. Nenhuma das fases de gestação apresentou deficiências severas no aporte proteico e energético da dieta, havendo a necessidade de adequação de cálcio e fósforo para o final da gestação.

PALAVRAS-CHAVE: Amazônia; déficit metabólico; dieta.

\author{
METABOLIC PROFILE OF SANTA INÊS SHEEP IN DIFERENT STAGES OF \\ PREGNANCY REARED IN SEMI-INTENSIVE SYSTEM IN STATE OF AMAZONIA
}

\section{ABSTRACT}

The aim of this study was to evaluate the nutritional metabolic condition of ewes at different stages of pregnancy. The analysis of the metabolic profile was through blood collection, using 30 sheep divided into three groups according to the stage of gestation (days): G1: between 50 and 60 days; G2: between 80 and 90 days, and G3: between 130 and 140 days. The analyzes of metabolites were performed by commercial kits. The concentrations of total protein, albumin, globulin and urea did not differ, except for urea, which showed increased levels. The mean glucose remained below the normal minimum value. For cholesterol, the means were 89.86 $\mathrm{mg} / \mathrm{dL}, 86.01 \mathrm{mg} / \mathrm{dL}$ and $92.23 \mathrm{mg} / \mathrm{dL}$ for G1, G2 and $\mathrm{G} 3$, respectively. The animals of $\mathrm{G} 1$ and $\mathrm{G} 2$ presented statistically similar means for triglycerides, differing from G3 animals. The $\beta$-hydroxybutyrate mean remained within the reference. Calcium levels were below the reference, showing the lowest level in G3 $(8.86 \mathrm{mg} / \mathrm{dL})$. Phosphorus levels decreased in G3. Any stage of pregnancy showed severe deficiencies in protein energy intake and diet, however requiring adequate calcium and phosphorus to the end of pregnancy.

KEYWORDS: Amazon; diet; metabolic deficit. 


\section{INTRODUÇÃO}

O Amazonas é o maior estado do país e possui mais de três milhões de habitantes, com quase metade residente na capital Manaus. Com relação aos pequenos ruminantes, o rebanho de ovinos e caprinos quadruplicou nos últimos cinco anos, possivelmente em função do aumento da demanda pela carne desses animais. De acordo com estimativas da Associação de Criadores de Ovinos e Caprinos do Amazonas (Acocam), em cinco anos, o número de animais subiu de $20 \mathrm{mil}$ para 100 mil cabeças.

A ovinocultura Amazonense está passando por um período de grandes transformações, principalmente no que se refere à cultura dos produtores, deixando de ser uma atividade de subsistência para fazer parte de um mercado em franca expansão, havendo uma forte demanda pela carne de cordeiro, mas também por matrizes, reprodutores, sêmen e embriões (1).

A otimização da fertilidade de um rebanho de ovinos é influenciada por uma série de fatores que levam machos e fêmeas garantirem gametas funcionais. Após a concepção, o ambiente uterino deve estar adequado ao desenvolvimento embrionário e fetal, propiciando a parição de crias vivas e vigorosas. (2). Durante todo o processo, os animais devem estar em condição de escore corporal adequada. Fêmeas bem nutridas, saudáveis e bem manejadas potencializam a antecipação do peso e idade ao abate em animais de corte e a precocidade reprodutiva em fêmeas e machos de corte ou de leite.

Em se tratando de parto simples ou gemelar, o período de gestação das ovelhas é sempre bastante crítico devendo-se dar atenção a questões nutricionais (3). Isso porque a condição de gestação eleva as necessidades alimentares, especialmente durante as últimas seis semanas, quando há um maior crescimento fetal. (4) Nessa fase, também ocorre um incremento das necessidades maternas de nutrientes para o desenvolvimento do úbere $\mathrm{e}$ da própria manutenção. (5)

A utilização dos métodos bioquímicos de avaliação da condição metabólica nutricional no período que antecede o parto e durante a lactação vem sendo aplicada na produção animal desde os anos 1970, quando pesquisadores da Universidade de Compton, na Inglaterra, desenvolveram um método de avaliação de vacas leiteiras pelo uso de amostragem, na qual avaliava componentes proteicos, energéticos e minerais. Atualmente, esses conhecimentos são aproveitados para outras espécies de interesse zootécnico (6). O tipo de gestação, a nutrição e as estações do ano podem ser responsáveis por alterações no perfil metabólico de fêmeas em atividade reprodutiva, por isso é de extrema importância a avaliação dos resultados bioquímicos correlacionando esses possíveis elementos de interferência $(7,8)$.

A toxemia da prenhez acomete caprinos e ovinos principalmente nas últimas seis semanas de gestação. $\mathrm{O}$ monitoramento dos padrões proteico, energético e mineral em ovinos é uma ferramenta de grande importância para a adequação alimentar e da condição metabólica de ovelhas considerando a pressão do processo de intensificação da produtividade, que, em muitos casos, promove os desequilíbrios entre o ingresso e egresso dos nutrientes, tornando-se, assim, um entrave para a produção animal (9).

O presente trabalho teve como objetivo avaliar a condição metabólica nutricional de ovelhas em diferentes fases de gestação, bem como a qualidade da dieta oferecida, diagnosticar possíveis transtornos metabólicos que ocasionem perdas econômicas ao produtor e enfermidades ao animal, contribuindo, dessa forma, com valores bioquímicos sorológicos de referência para a raça na região.

\section{MATERIAL E MÉTODOS}

O estudo foi realizado na propriedade Rebanho S Pedro, localizada no entorno de Manaus, na rodovia AM-010, $\mathrm{km} \mathrm{30,} \mathrm{a} 60^{\circ}$ de longitude oeste, $3^{\circ} 08^{\prime \prime}$ de latitude sul, distante $1.700 \mathrm{~km}$ em linha reta do litoral, com altitude de $92.9 \mathrm{~m}$. Apresenta características de clima equatorial úmido, com temperaturas médias anuais sempre acima de $22^{\circ} \mathrm{C}$, chuvas abundantes - 2.500 $\mathrm{mm}$, intensa radiação, elevada umidade do ar e baixas velocidades de ventos.

As análises laboratoriais foram realizadas no Laboratório de Bioquímica e Laboratório de Atividade Biológica da Universidade Federal do Amazonas - UFAM (análise bioquímica sorológica) e no Laboratório de Tecnologia do Pescado, também da UFAM (análise de composição centesimal da alimentação das ovelhas).

Os animais foram identificados 
individualmente por meio de colares e brincos na face distal da orelha.

A análise do perfil metabólico foi feita por meio de uma única coleta de sangue realizada pela manhã, utilizando-se 30 ovelhas com peso médio de $70 \mathrm{~kg}$ e idade variando de 2 a 3 anos, com escore de condição corporal (ECC) entre 3,0 e 3,5, em escala de 1 a 5 , na qual 1 corresponde a ovelhas muito magras e 5, a ovelhas obesas, segundo Morand-Fehr \& Hervieur (10). As ovelhas estavam clinicamente saudáveis. Os animais foram distribuídos em três grupos com 10 animais cada sendo $\mathrm{G} 1$ : ovelhas entre 50 e 60 dias de gestação; G2: ovelhas entre 80 e 90 dias de gestação; e G3: ovelhas entre 130 e 140 dias de gestação, representando o início, o meio e o fim da gestação, respectivamente.

As ovelhas tinham acesso a áreas de pastagem (Brachiaria dictyoneura) pelo período da manhã e eram estabuladas para o fornecimento da complementação alimentar, que consistia em $1,2 \mathrm{~kg}$ de concentrado/animal/dia (54\% de milho triturado, $30 \%$ de farelo soja, $15 \%$ de casca de soja e $1 \%$ de suplemento mineral), $4,8 \mathrm{~kg}$ de resíduo de cervejaria úmido/animal/dia e $4 \mathrm{~kg}$ de capim elefante (Pennisetum purpureum) triturado/animal/dia.

A coleta de sangue foi realizada por venipunção da jugular em tubos vacuolizados sem anticoagulante para obtenção do soro e em tubos contendo antiglicolítico fluoreto de sódio para análise de glicose. Após a coleta, as amostras ficaram em repouso até a total coagulação, foram centrifugadas por 10 minutos a $2500 \mathrm{rpm}$, transferindo-se o soro para micro tubos com capacidade de $0,5 \mathrm{~mL}$ para armazenamento e posterior análise.

As análises bioquímicas foram realizadas utilizando-se kits de diagnóstico com princípios metodológicos enzimáticos das empresas Labtest Diagnóstica $^{\circledR}$ S. A., BioClin ${ }^{\circledR}$ e Randox ${ }^{\circledR}$, seguindo seus respectivos protocolos. A leitura foi realizada em equipamento automatizado COBAS MIRA PLUS (Roche ${ }^{\circledR}$, Alemanha) para ureia, albumina, proteínas totais e fósforo e manualmente em espectrofotômetro de absorção para os demais metabólitos.

Os metabólitos avaliados foram os do metabolismo proteico (proteína total, ureia, albumina e globulina), energético (triglicerídeos, colesterol, glicose e beta-hidroxibutirato-BHB) e mineral (cálcio, fósforo e magnésio).

Os animais foram distribuídos em um delineamento experimental inteiramente casualizado com três tratamentos e 10 repetições. Os dados foram submetidos à análise de variância, por meio do programa estatístico SISVAR da Universidade Federal de Lavras e, quando necessário, as médias foram comparadas pelo teste Tukey ao nível de significância de $5 \%$ de probabilidade.

Tabela 1 - Composição centesimal do concentrado (54\% de milho triturado, $30 \%$ de farelo soja, $15 \%$ de casca de soja e $1 \%$ de suplemento mineral), do capim elefante (Pennisetum purpureum), da pastagem (Brachiaria dictyoneura) e do resíduo de cervejaria úmido em matéria integral (\%) fornecida para as ovelhas em gestação

\begin{tabular}{|c|c|c|c|c|c|c|c|c|c|}
\hline & $\mathrm{MS}^{1}$ & $\mathrm{~PB}^{2}$ & $\mathrm{EE}^{3}$ & $\mathrm{MM}^{4}$ & $\mathrm{FDN}^{5}$ & FDA $^{6}$ & $\mathrm{ENN}^{7}$ & $\mathrm{NDT}^{8}$ & $\begin{array}{c}\text { Energia } \\
\text { Digestível } \\
\text { (kcal } / \mathrm{kg} \text { ) }\end{array}$ \\
\hline Concentrado & 87,99 & 19,08 & 2,17 & 4,42 & 20,55 & 9,52 & 41,67 & 81,48 & 3592 \\
\hline $\begin{array}{l}\text { Capim Elefante } \\
\text { (Pennisetum } \\
\text { purpureum) }\end{array}$ & 25,80 & 4,26 & 0,53 & 0,92 & 75,00 & 43,80 & 11,16 & 54,77 & 2415 \\
\hline $\begin{array}{l}\text { Pastagem } \\
\text { (Brachiaria } \\
\text { dictyoneura) }\end{array}$ & 13,25 & 3,56 & 0,97 & 0,86 & 81,75 & 46,45 & 9,64 & 52,71 & 2324 \\
\hline $\begin{array}{l}\text { Resíduo de } \\
\text { Cervejaria } \\
\text { Úmido }\end{array}$ & 23,10 & 8,68 & 1,93 & 0,60 & 8,82 & 4,83 & 8,64 & 85,13 & 3753 \\
\hline
\end{tabular}

${ }^{1}$ Matéria seca; ${ }^{2}$ Proteína bruta; ${ }^{3}$ Extrato etéreo; ${ }^{4}$ Matéria mineral; ${ }^{5}$ Fibra em detergente neutro (\% em Matéria seca); ${ }^{6}$ Fibra em detergente ácido (\% em Matéria seca); ${ }^{7}$ Extrato não nitrogenado; ${ }^{8}$ Nutrientes digestíveis totais. 


\section{RESULTADOS E DISCUSSÃO}

Os valores médios das concentrações séricas de proteínas totais, albumina, globulinas e ureia em função da fase de gestação das ovelhas são apresentados na Tabela 2. Observou-se que os grupos avaliados não apresentaram diferença $(\mathrm{p}<$ $0,05)$ para os metabólitos proteicos que se mantiveram dentro dos limites de referência com exceção da ureia, que apresentou níveis aumentados.

Tabela 2 - Médias e erros-padrão para os níveis séricos dos metabólitos de ovelhas Santa Inês em diferentes fases de gestação

\begin{tabular}{lcccc}
\hline Parâmetros Analisados & \multicolumn{3}{c}{ Período de Gestação } & $\begin{array}{c}\text { Parâmetros de } \\
\text { Referência para } \\
\text { Ovinos* }\end{array}$ \\
\hline Metabolismo Proteico & Meio & Fim & $60-79$ \\
Proteínas Totais (g/L) & $68,02 \pm 10,12$ & $69,16 \pm 6,89$ & $68,75 \pm 16,04$ & $26-42$ \\
Albumina (g/L) & $31,00 \pm 3,80$ & $30,40 \pm 2,95$ & $31,80 \pm 1,69$ & $35-57$ \\
Globulina (g/L) & $37,02 \pm 9,37$ & $38,76 \pm 7,06$ & $36,95 \pm 16,29$ & $17-43$ \\
Ureia (mg/100mL) & $45,80 \pm 7,50$ & $45,10 \pm 14,30$ & $49,80 \pm 8,94$ & \\
Metabolismo Energético & & & & $50-80$ \\
Glicose (mg/100mL) & $38,58 \pm 7,39$ & $39,37 \pm 11,06$ & $44,29 \pm 7,84$ & $52-76$ \\
Colesterol (mg/100mL) & $89,86 \pm 9,40$ & $86,01 \pm 5,97$ & $92,23 \pm 12,69$ & SRL \\
Triglicerídeos (mg/100mL) & $73,09 \pm 2,81^{\text {a }}$ & $72,94 \pm 4,52^{\text {a }}$ & $81,24 \pm 6,93^{\mathrm{b}}$ & $<0,6$ \\
B-hidroxibutirato (mmol/L) & $0,22 \pm 0,11$ & $0,22 \pm 0,08$ & $0,26 \pm 0,11$ & $11,5-12,8$ \\
Metabolismo Mineral & & & & $5,0-7,3$ \\
Cálcio (mg/100mL) & $9,39 \pm 0,54$ & $9,22 \pm 0,84$ & $8,86 \pm 1,15$ & $2,2-2,8$ \\
Fósforo (mg/100mL) & $7,15 \pm 1,36^{\text {ab }}$ & $7,42 \pm 1,35^{\text {b }}$ & $5,88 \pm 0,82^{\text {a }}$ & \\
Magnésio (mg/100mL) & $2,32 \pm 0,23$ & $2,33 \pm 0,19$ & $2,34 \pm 0,14$ & \\
\hline
\end{tabular}

Médias seguidas de letras distintas na mesma linha diferem $(\mathrm{P}<0,05)$ pelo teste Tukey.

SRL: Sem referência na literatura.

*Kaneko (20).

Em outros países (11) e no Rio Grande do Sul (12), observando ovelhas em pastoreio, foi encontrada uma redução desses metabólitos com o avanço da gestação e da lactação, provavelmente pela baixa ingestão de proteína durante essa fase.

De acordo com o NRC (13), ovelhas no final da gestação possuem um requerimento em proteína bruta de $193 \mathrm{~g} / \mathrm{PB} / \mathrm{dia}$. No presente trabalho, as ovelhas tiveram um consumo médio de proteínas (396g PB/dia) superior à recomendada para as três fases de gestação.

Níveis séricos de ureia e albumina são os principais indicadores do metabolismo proteico em ruminantes. A ureia demonstra o estado proteico em curto prazo, enquanto a albumina o demonstra em longo prazo. Conforme descrito por Wittwer et al. (14), a ureia é sintetizada no fígado em quantidades proporcionais à concentração de amônia produzida no rúmen e sua concentração está diretamente relacionada aos níveis proteicos da ração e à relação energia/proteína da dieta. A albumina é considerada o indicador mais sensível para determinar o estado nutricional proteico, de modo que valores persistentemente baixos sugerem inadequado consumo proteico.

Existe forte correlação entre o nível plasmático de ureia e a quantidade de proteína ingerida. O principal fator controlador dos níveis de ureia no plasma é a formação de amônia no rúmen e o nível de ureia no sangue parece refletir as modificações na produção de amônia ruminal. Dessa forma, a concentração de ureia no sangue é influenciada pela extensão na qual os aminoácidos absorvidos são oxidados e pela absorção de amônia do rúmen, refletindo substancialmente a extensão do balanço de nitrogênio da dieta, considerando-se tanto as exigências dos microrganismos ruminais como as do animal hospedeiro (14).

Maior parte (cerca de 60\%) da proteína dietética ingerida pelo animal é degradada no rúmen em compostos simples como aminoácidos, amônia e ácidos graxos voláteis, produtos estes que podem ser transformados em proteína microbiana. Contudo, essa síntese pode ser prejudicada pela ausência de energia ou por falta de nitrogênio. A proteína que não é degradada no rúmen (PNDR) pode ser digerida 
e absorvida na forma de aminoácidos, no intestino delgado.

Os níveis de PNDR apresentam certa variação do nitrogênio das forragens e silagens (em torno de 0 a $25 \%$ ). A amônia em excesso, que é produzida no rúmen, vai para a corrente sanguínea, sendo levada então ao fígado e transformada em ureia, podendo ser utilizada como fonte de nitrogênio ou permanecer circulante no sangue ou, ainda, ser excretada pela urina.

Os níveis de ureia, além de estarem relacionados com os níveis de proteínas da dieta, também refletem a relação energia/ proteína da dieta e o seu equilíbrio é essencial para seu bom aproveitamento. Quanto maior for a ingestão de proteína alimentar, maiores serão os níveis de ureia no sangue e, quando a ingestão de proteínas for insuficiente, menores serão os níveis de ureia no sangue (15).

As médias de glicose não foram diferentes estatisticamente, apresentando uma concentração numericamente crescente com o avanço da gestação e abaixo do valor normal mínimo para ovinos que é de 50 a $80 \mathrm{mg} / \mathrm{dL}$. Nas últimas seis semanas de gestação, ocorre um aumento das necessidades de nutrientes e, principalmente, energia, devido ao crescimento fetal, em que o feto atinge até $80 \%$ do seu tamanho e peso final (16).

No presente estudo, os valores das médias de colesterol para os animais no início, no meio e no fim da gestação foram $89,86 \mathrm{mg} / \mathrm{dL}, 86,01 \mathrm{mg} / \mathrm{dL}$ e $92,23 \mathrm{mg} / \mathrm{dL}$, respectivamente. As médias não diferiram estatisticamente entre si $(p<0,05)$, mas foram superiores aos valores de referência (1).

Não há na literatura valores de referência para triglicerídeos de ovinos. Os animais que estavam no início e no meio da gestação tiveram médias de triglicerídeos estatisticamente iguais $(\mathrm{p}<0,05)$ sendo $73,09 \mathrm{mg} / \mathrm{dL}$ e $72,94 \mathrm{mg} / \mathrm{dL}$, respectivamente, diferindo da média dos animais no final da gestação $(81,24 \mathrm{mg} / \mathrm{dL})$.

Uma explicação para níveis altos de colesterol e triglicerídeos circulantes seria devido à mobilização de energia do tecido adiposo decorrente de um déficit energético na dieta dos animais estudados o que não se justifica quando se avaliam as médias de $\beta$-hidroxibutirato que não apresentaram diferença estatística e mantiveram-se dentro dos padrões de referência para ovinos $(<0,6 \mathrm{mmol} / \mathrm{L})$.

$\mathrm{O}$ aumento nos níveis de BHB na gestação e lactação coincidem com $\mathrm{o}$ período de maior crescimento fetal e de desenvolvimento do úbere, assim como de uma maior demanda de glicose para a síntese de leite.

A variação de $\beta$-hidroxibutirato (BHB) não foi expressiva nas três fases de gestação. Esse fato pode ser atribuído às características genéticas e adaptativas desses animais, relacionadas ao sistema de criação e a alimentação utilizada na região amazônica. As ovelhas encontravam-se com bom ECC (3-3,5), possibilitando reservas de energia. Tais características são de extrema importância no controle de transtornos metabólicos como a toxemia (17).

Os valores obtidos neste estudo tanto para triglicerídeos quanto para colesterol, bem como as médias de $\beta$-hidroxibutirato sugerem um aporte energético suficiente para as ovelhas estudadas, levando-se em consideração que os animais apresentavam ECC satisfatório (18).

Os minerais têm fundamental importância na nutrição, em virtude da sua participação na utilização da energia, daproteína dietética e da biossíntese dos nutrientes. $O$ cálcio não é um bom indicador do estado nutricional do rebanho devido ao controle rigoroso da calcemia, enquanto o fósforo e o magnésio refletem melhor o status nutricional mineral (14).

Os níveis séricos de cálcio estiveram sempre abaixo dos valores de referência (19), mostrando comportamento semelhante ao descrito por Ribeiro et al. (2). Nota-se que o valor mais baixo desse mineral foi observado no final da gestação $(8,86$ $\mathrm{mg} / \mathrm{dL}$ ), quando ocorre a maior demanda de cálcio para o crescimento ósseo do feto e produção de leite.

Os níveis séricos de magnésio mantiveramse dentro dos padrões de referência (Tabela 2) e apresentaram-se estatisticamente iguais para os três grupos, mostrando que o balanço desse mineral foi adequado para o período gestacional.

Durante o terço final da gestação, a concentração sorológica de fósforo diminuiu $(5,88$ $\mathrm{mg} / \mathrm{dL})$, sendo significativamente $(\mathrm{p}<0,05)$ diferente da concentração dos animais no início da gestação $(7,15 \mathrm{mg} / \mathrm{dL})$. Esse fato pode indicar uma deficiência de fósforo no solo e consequentemente na pastagem da região, levando em consideração o requerimento de fósforo por ovelhas no terço final da gestação.

\section{CONCLUSÃO}

Os dados deste experimento sugerem que nenhuma das fases de gestação apresentou deficiências severas no aporte proteico e energético da dieta, podendo essa dieta ser utilizada na alimentação de ovelhas em fase de gestação, em sistema semi-intensivo no Amazonas.

O cálcio apresentou seus níveis diminuídos durante as três fases de gestação, havendo a necessidade da adequação dos níveis desse mineral na dieta. 


\section{REFERÊNCIAS}

1. Oliveira GJC, Jaeger SMPL, Oliveira RL, Marques JA, Bagaldo AR. Nutrição, produtividade e rentabilidade econômica na caprinovinocultura. Capril Virtual, 2008.

2. Russel AJF. Relationship between energy intake, nutritional state and lamb birth weight in Greyface ewes. Journal Agricultural Science. 2003; 34 (9):667-673.

3. Fernandes CAC. Aspectos nutricionais relacionados a doadoras e receptoras de embrião. Acta Scientiae Veterinariae. 2003; 31:137-146.

4. Pires CC, Silva LD, Schlick, FE, Guerra DP, Biscaino G, Carneiro RM. Cria e terminação de cordeiros confinados. Ciência Rural. 2000; 30(5), 875-880.

5. Ribeiro LAO, Diaz Gonzalez FH, Conceição TR, Brito MA, La Rosa VL, Campos R. Perfil metabólico de borregas Corriedale em pastagem nativa do Rio Grande do Sul. Acta scientiae veterinariae. 2003; 31(3):167-170.

6. Macedo Junior GL, França PM, Assis RM, Almeida TRV, Paula OJ, Pérez JRO, Silva VB. Level of fiber on feeding of Santa Ines pregnant ewes. Arq. Bras.Med.Vet. Zootec. 2009; 61(1):196-202.

7. Brito MA, González FD, Ribeiro LA, Campos R, Barbosa PR, Bergman G. Composição do sangue e do leite em ovinos leiteiros do sul do Brasil: variações na gestação e lactação. Ciência Rural. 2006; 36(3):1-7.

8. Balikci E, Yildiz A, Gürdogan F. Blood metabolite concentration during pregnancy and postpartum in Akkaraman ewes. Small Ruminant Research. 2007; 67(2): 247-251.

9. Caldeira RM. Monitoração da adequação do plano alimentar e do estado nutricional em ovelhas. Revista Portuguesa de Ciências Veterinárias. 2005; 100(555556):125-139.

10. Morand-Fehr P. Hervieu J. Apprécier l'état corporel des chèvres: Intérêt et méthod. Reussir La Chèvre. 1999; 231:22-34.

11. Wittwer F, Reyes JM, Opitz H. Determinación de urea en muestras de leche de rebaños bovinos para el diagnostico de desbalance nutricional. Archivo Medico Veterinario. 2000; 25:165-172.

12. Ribeiro LAO, Mattos R C, González FH, Lopes D, Wald VB, Silva MAD, La Rosa VL. Perfil metabólico de ovelhas Border Leicester x Texel durante a gestação e lactação. Revista Portuguesa de Ciências Veterinárias. 2004; 99(551):155-159.

13. National Research Council - NRC. Nutrient requirements of small ruminants: sheep, goats, cervids and new world camelids. Washington: National Academy Press; 2007. 362p.

14. Lima PMT. Parâmetros hematológicos, bioquímicos, ganho em peso e emissão de metano de ovinos Santa Inês alimentados com coprodutos do algodão [dissertação]. Brasília: Faculdade de Agronomia e Medicina Veterinária, Universidade de Brasília; 2013. 63p.

15. Cardoso EC, Oliveira DR, Dourado AP, Araújo CV, Ortalani EL, Brandão FZ. Peso e condição corporal, contagem de OPG e perfil metabólico sanguíneo de ovelhas da raça Santa Inês no periparto, criadas na região da Baixada Litorânea do Estado do Rio de Janeiro. Revista Brasileira de Ciência Veterinária.2010; 17(2):7782.

16. Rodrigues $\mathrm{CAF}$, Rodrigues $\mathrm{MT}$, Branco $\mathrm{RH}$, de Queiroz AC, de Araújo CV. Influência da condição corporal e da concentração de energia nas dietas no periparto sobre o desempenho de cabras em lactação. Revista Brasileira de Zootecnia. 2006; 35(4):1560-1567.

17. Bezerra LR, Ferreira AF, Camboim EKA, Justiniano SV, Machado PCR, Gomes BB. Perfil hematológico de cabras clinicamente sadias criadas no Cariri paraibano. Ciênc. agrotec. 2008; 32(3):955-960.

18. Costa NL, Magalhães JA, Pereira R, Townsend C. Efeito da carga animal sobre o ganho de peso de ovelhas da raça Morada Nova em pastagens de Brachiaria humidicola. Redevet. Revista Electrónica de Veterinaria [internet]. 2006 [citado 2011 outubro 09]; VII(8):1-5 Disponível em: http://redalyc.uaemex.mx/src/inicio/ArtPdfRed.jsp?iCve= 63612750010. ISSN.

19. Barioni G, Fonteque HJ, Paes PRO, Takahira RK, Kohayagawa ARS, Lopes STA, Crocc AJ. Valores séricos de $\mathrm{Ca}, \mathrm{P}$, sódio, potássio e proteínas totais em caprinos fêmeas da raça parda alpina. Revista Ciência Rural. 2007; 31(3):435-438.

20. Kaneko JJ, Harvey JW, Bruss ML. Appendixes. Kaneko JJ. Clinical biochemistry of domestic animals. 1997. 877-901. 